\title{
O Tempo em Análise !!!
}

O tempo é um tema que vem há vários anos sendo debatido como um tópico polêmico e controvertido dentro da Psicologia e sobretudo dentro da Psicanálise. Ele versa não só sobre a duração de um tratamento, mas também sobre quanto tempo dura cada sessão, vertente da discussão que se acentuou principalmente quando da chegada da teoria lacaniana nesse debate. $\mathrm{O}$ presente trabalho, portanto, visa fazer esse percurso de maneira pontual, aprofundando-se na vertente da Psicanálise lacaniana, abordando a questão das sessões curtas e a polêmica utilização do tempo lógico.

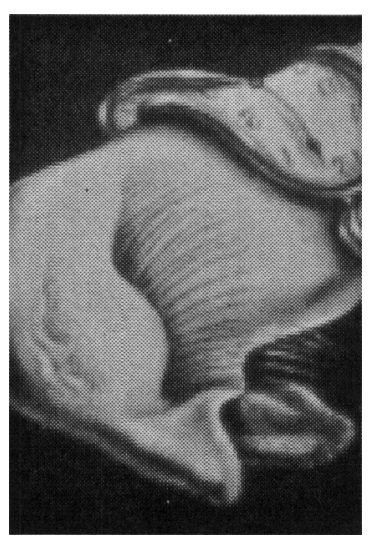

Ana Aparecida Nascimento Martinelli Braga Psicanalisto (Pós-Graduoda PUC/RJ) Psicóloga Clínica

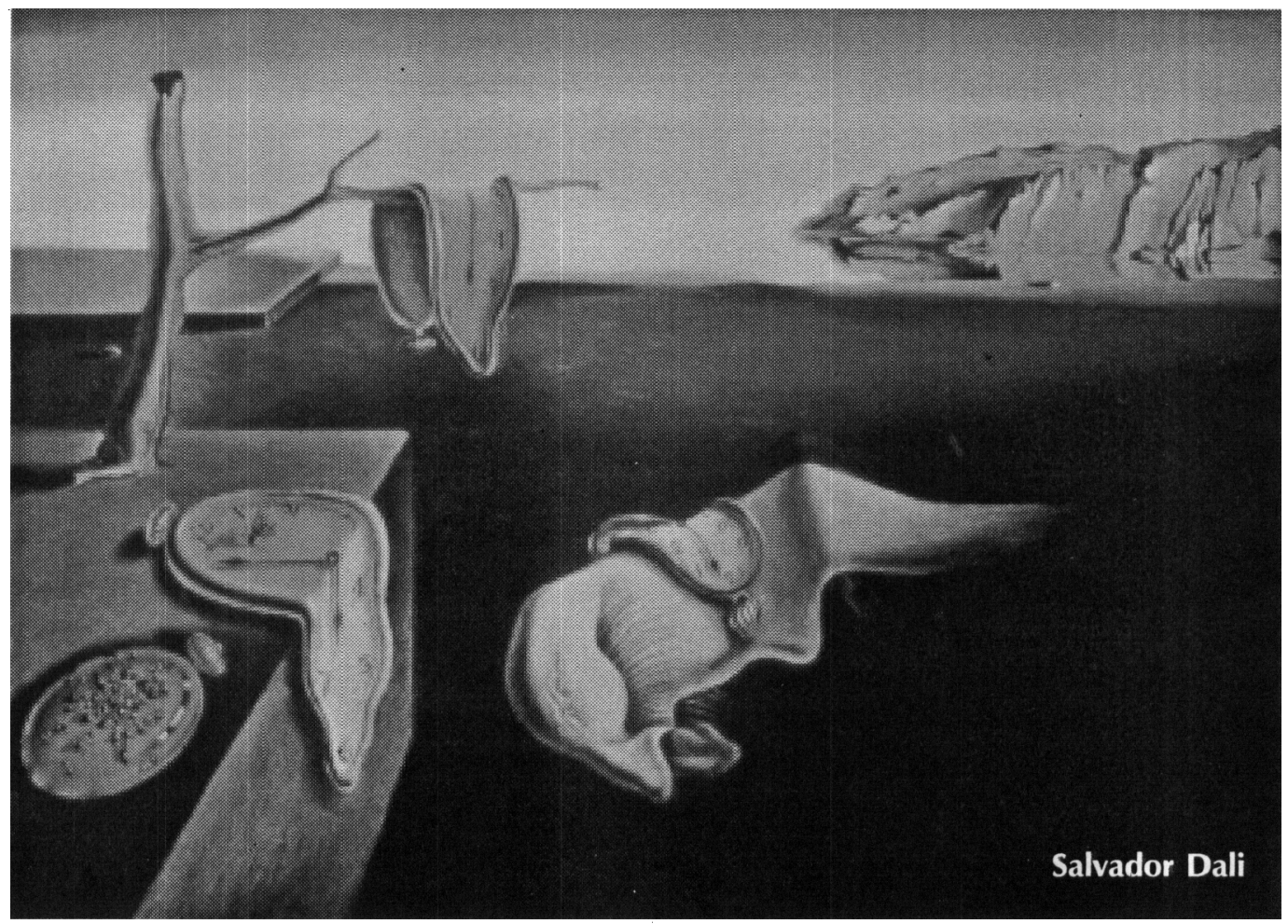

"Uma pergunta importuna que o paciente faz ao médico, no início, é: 'Quanto tempo durará o tratamento. De quanto tempo o senhor precisará para aliviar-me de meu problema?' Se se propôs um tratamento experimental de algumas semanas, pode-se evitar fornecer resposta direta a esta pergunta, prometendose fazer um pronunciamento mais fidedigno ao final do período de prova. Nossa resposta assemelha-se à resposta dada pelo Filósofo ao Caminhante, na fábula de Esopo. Quando o caminhante perguntou ao Caminhante quanto tempo teria de jornada, o Filósofo simplesmente respondeu 'Caminha!' e justificou sua resposta aparentemente inútil, com o pretexto de que precisava saber a amplitude do passo do Caminhante antes de Ihe poder dizer quanto tempo a viagem duraria. Este expediente auxilia-nos a superar as primeiras dificuldades, mas a comparação não é boa, pois o neurótico pode facilmente alterar o passo e, às vezes, fazer apenas progresso muito lento. Na verdade, a pergunta relativa à duração de um tratamento é quase irrespondível." (Freud, 1913/1969, págs.169-170) 
O que constatamos na clínica é que muitos pacientes começam um processo de atendimento, seja ele uma psicoterapia ou uma psicanálise, muito curiosos e ansiosos acerca do término, do final do tratamento. Ficam intrigados com o que se passa sobre essa questão e chegam a falar, já nessa ocasião, com o psicólogo/psicanalista, sobre o que os levaria a, ao começar um tratamento, já estarem "curiosos" com o final. Enfim, muitas "águas rolam" durante o tratamento, muito tempo também e depois eles vão se dando conta das suas próprias questões e das suas variadas amplitudes de passos no seu caminhar único e particular. $\mathrm{Na}$ verdade, o que percebemos é que a angústia é o sinal de que algo do real está ameaçando aparecer. Há uma angústia no início, que remete à angústia do final, daí um dos motivos de, desde o começo, já se visualizar a conclusão do tratamento.

Através da teoria, mas também e principalmente da experiência clínica, pode-se constatar hoje que o tempo em análise é uma questão bastante relativa. Falo aqui não só do tempo que leva uma sessão, mas também de quanto tempo dura uma análise. Para cada paciente há que se ater à sua particularidade; o psicanalista deve tomar cada caso clínico, cada nova pessoa que lhe chega ao consultório com uma demanda de análise, como se fosse o primeiro, e o tempo vem como uma questão que também deve ser vista caso a caso.

Freud, no começo da sua prática e dos seus estudos, logo se deparou com uma certa dificuldade com essa questão. Atendia diariamente, de segunda a sábado as suas pacientes, só não domingos e feriados. $\mathrm{O}$ tempo da sessão era de uma hora e as suas intervençōes eram da ordem de interpretações tradutivas, quer dizer, ele buscava traduzir a fala da paciente. Contudo ele tinha problemas em manter as pacientes em análise, elas não ficavam. As chamadas "resistências" apareceram e foram nomeadas; a partir daí surgiu um outro modelo de intervenção terapêutica, onde $o$ analista deveria empreender uma "batalha" contra as resistências da paciente.

Tudo isso foi uma experiência, foi uma prática rica em aprendizado. Desse período sabemos da existência de profissionais vinculados a essas correntes, quais sejam: a arte interpretativa de Melanie Klein, onde se utiliza como técnica terapêutica a interpretação dos conteúdos trazidos pelo paciente; ou também a psicanálise do ego, desenvolvida por Anna Freud, através da qual busca-se dissolver as resistências do paciente.

Freud escutou bem todas as suas pacientes histéricas que the pediram pra falar, the pediram que as escutasse. $E$ assim foi, Freud estava aberto a aprender também com as suas pacientes.

Mas por que falar sobre interpretação e intervenção do analista, se o tema em debate nesse trabalho é "Tempo em análise", tempo em questão? Faz-se necessária essa introdução, posto que nesse enfoque fala-se sobre transferência, que é o tempo da análise.

"A que isso nos conduz? - senão a colocar de novo que o conceito é o tempo. Nesse sentido, pode-se dizer que a transferência é o conceito mesmo da análise, porque é o tempo da análise." (Lacan, 1954/1983, pág. 325)

Nesse período, o que se colocava como problema era que os atendimentos duravam muito pouco, mas não porque havia se chegado a um final propriamente dito, mas sim porque as "histéricas" iam embora ao serem interpretadas. Contudo, ao contrário de não saber manter as pacientes em análise, com os pacientes obsessivos Freud se deparou com uma questão de não saber como fazê-los ir embora. Ele, ao embaraçar-se com a questāo da transferência, comenta que no início tinha dificuldade para manter os pacientes em atendimento, entretanto depois a dificuldade se inverte: já não sabe como fazer para fazê-los ir embora, como finalizar ou concluir o processo de atendimento. E uma análise deve ter um fim, ela não deve durar para sempre. Contudo esse fim deve ser marcado pelo próprio paciente, através do seu ato analítico por excelência de autorizar-se analista.

O verdadeiro ato analítico é o qual o analisante se autoriza analista; é o ato por excelência, pelo qual $o$ analisante se torna analista e marca 
o final de análise. Mesmo que não haja um término naquele momento, no sentido de interrupção, mesmo que o paciente continue indo para a análise, há um final clínico e muitas vezes ele necessita ainda "freqüentar o divā" para então ir se desligando efetivamente do ạnalista e da análise. Esse ato ressignifica para o sujeito a sua entrada em análise, que também é marcada por um ato, não só seu, de procurar um análise, mas do analista, que o aceitou em análise. A questão inicial da queixa, com o deslizamento para o sintoma, implicando a fantasia, torna-se aí marcante.

Numa entrada em análise se trata de fazer existir o inconsciente, através da regra fundamental "Diga tudo o que lhe vier à

\section{"eu penso" do início de análise é sustentado pelo Sujeito Suposto Saber, pelo analista que pensa.}

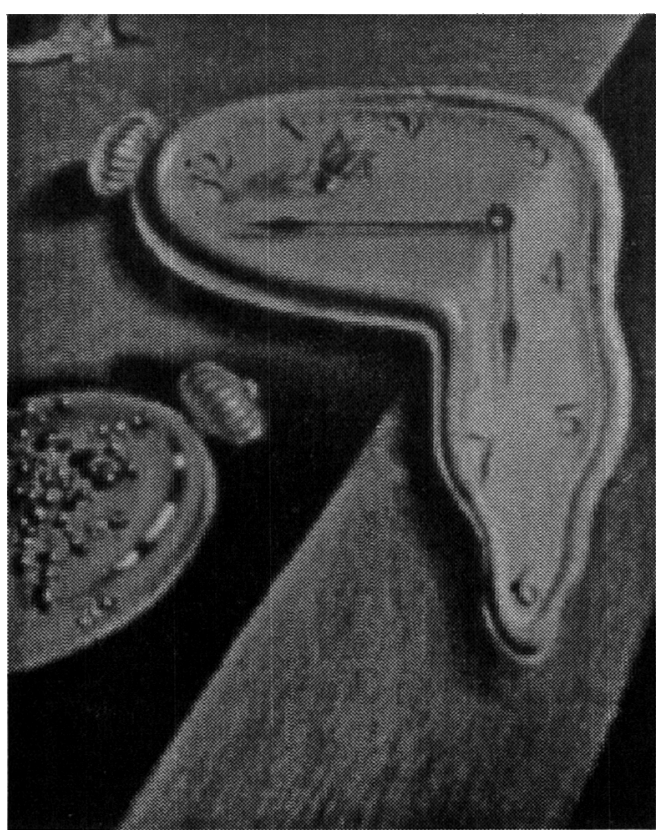

cabeça", quer dizer: pense. Esse "eu penso" do início de análise é sustentado pelo Sujeito Suposto Saber, pelo analista que pensa. A entrada em análise está do lado do "eu penso", do lado do inconsciente, já que é a linguagem do inconsciente, enquanto atemporal, que está em jogo numa análise. Lembremos que aqui trabalha-se com o inconsciente, que tem como propriedades: ausência de contradição, caráter atemporal e realidade psíquica.

Entretanto, o final de análise está do lado do "sou, logo não penso", está do lado do real, e não do simbólico; o final de análise vai contra $o$ inconsciente. Enquanto o analista faz o inconsciente funcionar, produzindo deciframentos, sentido, encadeamento lógico; o ato vai contra, instaurando uma descontinuidade, apontando para o sem sentido, fora da lógica, que desconserta o sujeito, fazendo-o mudar de posição diante da sua fantasia particular.

Cada sessão tem um "flash" da análise inteira, quer dizer, todo final da sessão remete a um final da análise, cada sessão contem o final da análise. $O$ ato analítico final ressignifica todos os atos anteriores da análise. $\mathrm{O}$ ato, mesmo no corte da sessão, vai contra o saber, vai contra o pensamento, a fala. Diferentemente de dar sentido ao dizer do paciente, fazendo interpretações tradutoras, o analista busca levantar questões, abrir a cadeia significante do sujeito, para fazê-lo deslizar. Para que haja um final de análise, deve-se falar em destituição subjetiva e em atravessamento da fantasia. $O$ que ocorre, então?

Ao longo de uma análise, o sujeito vai sendo levado a abandonar os significantes pelos quais ele se representa. Há uma destituição do sujeito do inconsciente, que é efeito do significante. $O$ sujeito abre mão dos significantes que fazem parte do ideal do eu, abre mão dos seus ideais e destitui o Outro, destitui o analista enquanto sujeito suposto saber. Então, com a queda dos ideais, com a queda do Grande Outro, marca-se a constatação para o sujeito da inconsistência do outro, marcando uma perda de referências para o sujeito. Isso é o que caracteriza o "não penso", o sujeito passa a agir sem pensar, com as pulsōes libertas dos seus representantes originais, mantendo, entretanto, uma grande responsabilidade pelos seus atos e suas conseqüências, já que passa a se implicar no seu dizer. A experiência da fantasia fundamental se torna pulsão, liberta das representações originais. "Eu não penso, logo sou um ser de pura falta": ao final da análise o sujeito se depara com a faltaa-ser, ser um ser de pura falta, como diz Freud, o sujeito se depara com o rochedo da castração. Lacan diz "Fazer da castração sujeito". Levar o sujeito ao ponto de se experimentar como falta. 
"A vertente da análise que implica a decifração do inconsciente e o sujeito como efeito do significante é interminável. Jamais se poderá saber tudo devido ao recalque primário. Só a partir do ponto da estrutura fora do significante, onde se denota o ser do sujeito (o sujeito é falta-a-ser), é que um final de análise é possível." (Quinet, 1991, pág.111)

Como falar dessas questōes dentro de um "contrato" pré-estabelecido de tempo? Seja de tempo para a duração da sessão, seja de tempo de duração da análise, visto que ambos são correlatos. Se o que regula o ato está para o lado do ser, do "sou onde não penso", e, portanto do não-saber a priori, encontra-se, então, fora do âmbito da análise, todo tipo de previsão, de fixação prévia de prazo.

No sofisma dos três prisioneiros, Lacan (1966/ 1996) fala do tempo lógico, dentro de um tempo curto, já que a pressa traz consigo a certeza antecipada do ato, que finaliza. Ele apresenta três partes, quais sejam:

1 - instante de olhar

2- tempo de compreender - certeza antecipada pela pressa

3 - momento de concluir

Lacan diz: "Não se deve levar uma análise longe demais." E completa Quinet, "ao se entrar numa sessão sem saber quanto tempo ela durará, se está sob o impacto da pressa, o que precipita o momento de concluir." (Quinet, 1991, pág. 74)

Enquanto Freud diz que a pulsão está entre o somático e o psíquico, Lacan diz que a pulsão está entre o simbólico (significantes) e o real (libido). O contrato, então, iria na vertente do contra-ato, impedindo que o sujeito se expressasse de maneira associativamente livre e desprendido dos ideais.

Não se prevê nem se planeja o tempo, mas Freud diz que a análise é finita e Lacan diz que deve ser "curta", deve-se ter pressa. Apesar de questóes profundas do sujeito tomarem um certo tempo, não se pode prolongar um tratamento desnecessariamente; o que está em jogo é a ética do desejo.
Devo fazer menção aqui a um último ponto que considero fundamental, que diz respeito à análise do analista. Enfim, estou falando de um fim possível, na medida em que o próprio analista possibilita isto, visto ter passado, ele próprio, ao menos por um certo atravessamento da sua fantasia pessoal. Só com a possibilidade do analista fazer-se de conta de objeto a é que ele pode presentificar a certeza antecipada do analisante no momento de concluir sua análise, ao fazer o atravessamento da fantasia $(\mathbf{8} \longrightarrow \mathbf{a})$.

"Evidentemente, não podemos exigir que o analista em perspectiva seja um ser perfeito antes que assuma a análise, ou em outras palavras, que somente pessoas de alta e rara perfeição ingressem na profissão. Mas onde e como pode o pobre infeliz adquirir as qualificações ideais de que necessitará em sua profissão? A resposta é: na análise de si mesmo, com a qual começa sua preparação para a futura atividade." (Freud, 1937/1969, pág. 282)

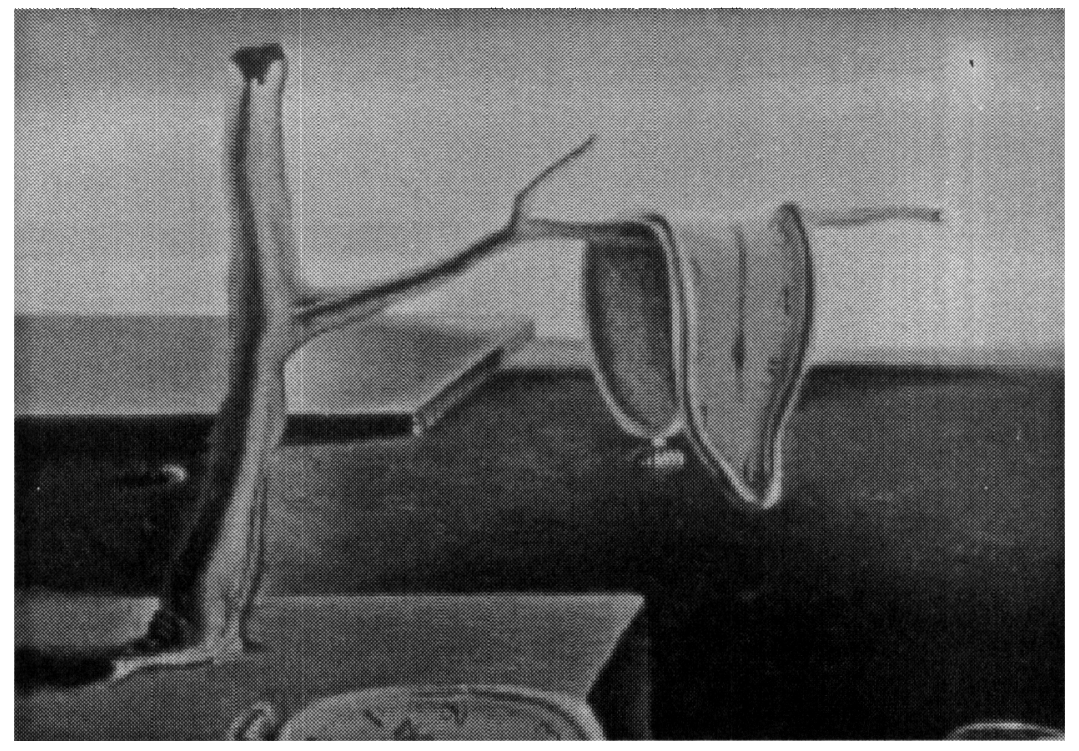

Deixar o paciente deslizar eternamente na sua cadeia de significantes, levaria a análise a um tempo infinito, pois sempre teria algo mais a dizer. Aí há que existir o ato, para trazer a marca do real, do nada, da falta, que marca o ser do sujeito. 
Sendo assim, a pressa diz respeito não só à sessão curta para o paciente, que fica submetido ao inesperado, ao imprevisível, podendo se deixar levar pelo seu inconsciente, pelo tempo lógico do seu inconsciente, mas também a tempos mais curtos e finitos de análise, aonde o sujeito vai fazer a travessia que leva da sua impotência à impossibilidade da estrutura, viabilizando o seu funcionamento, a sua mudança de posição diante das suas questões.
A partir da escuta do paciente na sua singularidade, o analista pode e deve fazer cortes, para que esse tempo não seja eterno, mas que ao contrário, tenha uma finitude, já que como nos disse Freud (1937/1969): a análise é infinita (sua vertente simbólica), mas também finita, já nos disse ele (na vertente do real).

Ana Aparecide Nascimenta Martinelli Braga Rua Humberto de Campos, 233, ap. 1003 Craga, SatradoritA - CEP: 40150-130 Fe(. (071) $351.3728 /$ (07 1) $336-3327$ emaki: mantrage@epunet.com.br

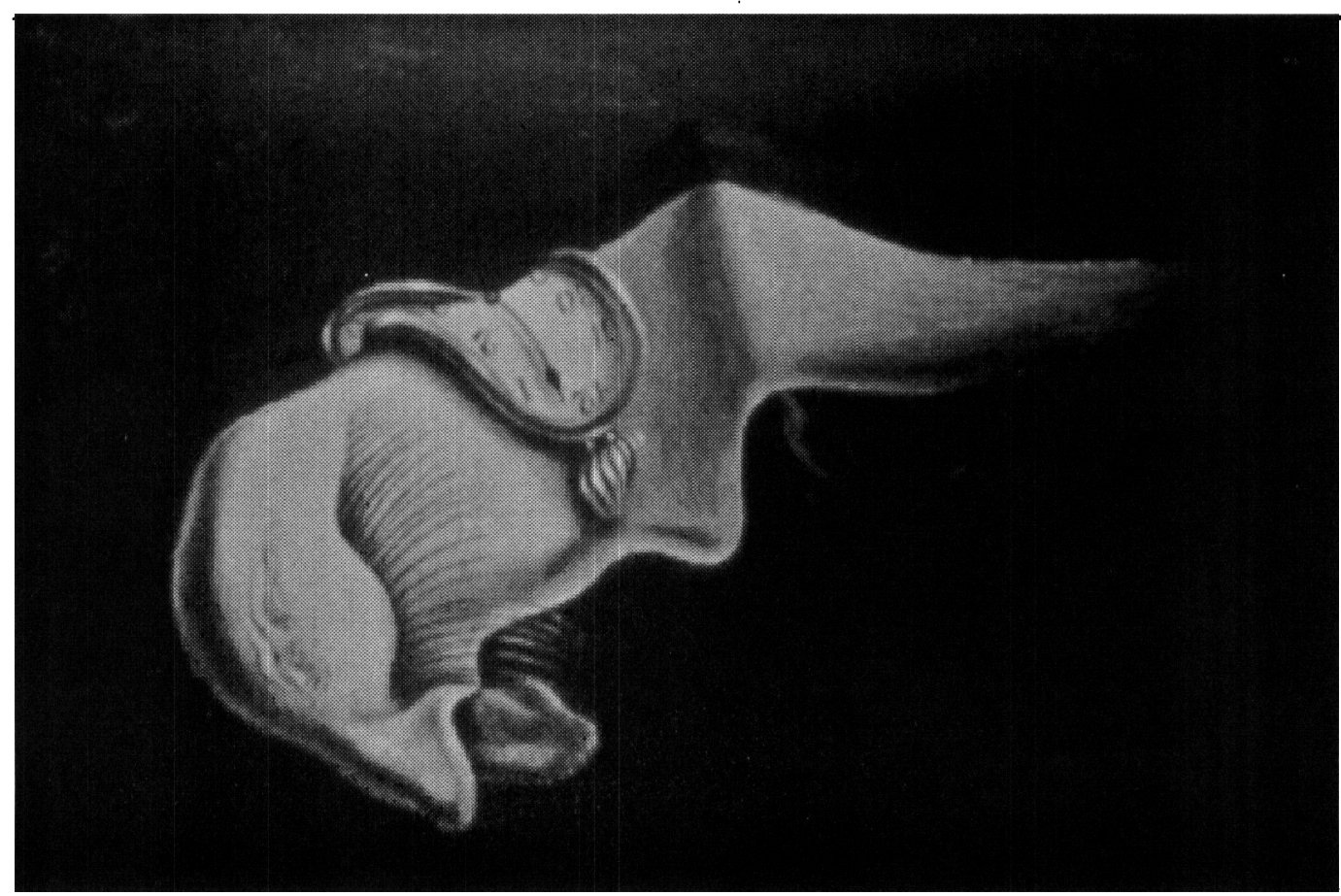


Freud, S. (1969) . Obras Completas . Ediçāo Standard Brasileira, Rio de Janeiro: Imago.

- Sobre o Início do Tratamento (Novas Recomendaçōes Sobre a Técrica da Psicanálise ) - vol. XII (Originalmente publicado em 1913)

- Análise Eeminávele Intermináve/-vol. XXIII (Originalmente publicado em 1937)

Lacan, J. (1983). OSeminário-Livmo1: Os Escritos Técnicos de Freud. Rio de Janeiro: Jorge Zahar Editor, $3^{\mathbf{a}}$ ediçāo.

- O Conceito da Análise (Originalmente publicado em 1954)

(1996) . Escritos. São Paulo: Editora Perspectiva.

- Tempo Lógico e a Asserção da Certeza Antecipada - Um Novo Sofisma (Originalmente publicado em 1966)
Quinet, A. (1991) . As4 + 1 Condiçōes de Análise . Rio de Janeiro: Jorge Zahar Editor, 4* ediçāo.

(Cap. III) - Que Tempo Para a Análise?

(Cap. V) - OAto Psicanaltico e o Fim de Análise

Soler, C. (1995). Variáveis do Fim daAnálise . Campinas/S.P.Papirus. - A Equação do Fim da Análise, em: "Freud e Lacan Sobre o Fim da Análise" (cap. l)

Textos Reunidos Pela Associação Mundial de Psicanálise - A.M.P. (1995). Como Terminam as Análises. Rio de Janeiro: Jorge Zahar Editor.

- A Pressa de Concluir de Freud, em "Os Anos Vinte: O Nascimento da Questão"

- A Forga Pulsional em Açāo, em "A Análise e Seu Resto: O Testamento de Freud"
Referências

bibliográficas 